\title{
Moving beyond insularity in the history, philosophy, and sociology of chemistry
}

\author{
Jeffrey I. Seeman ${ }^{1}$
}

Published online: 9 August 2017

(C) Springer Science+Business Media B.V. 2017

\begin{abstract}
This essay supports and encourages multiple disciplinary interactions for practitioners of the disciplines of chemistry, history of chemistry, philosophy of chemistry, and sociology of chemistry.
\end{abstract}

Keywords Multidisciplinarity · Interdisciplinarity · History of chemistry · Philosophy of chemistry - Sociology of chemistry

We have everything in common with "America" nowadays except, of course, language.

\section{Disciplinary isolation ${ }^{1}$}

Consider the following four disciplines:

(1) Chemistry,

(2) History of chemistry,

\footnotetext{
${ }^{1}$ In this essay, the terms "multidisciplinary," "interdisciplinary," and "multiple disciplinary" follow the definitions of Choi and Pak (2006) as follows: "Multidisciplinarity draws on knowledge from different disciplines but stays within their boundaries [i.e., additive]. Interdisciplinarity analyzes, synthesizes and harmonizes links between disciplines into a coordinated and coherent whole [i.e., interactive]. The more general term 'multiple disciplinary' is suggested for when the nature of involvement of multiple disciplines is unknown or unspecified."
}

Jeffrey I. Seeman

jseeman@richmond.edu

1 Department of Chemistry, University of Richmond, Richmond, VA 23173, USA 
(3) Philosophy of chemistry, and

(4) Sociology of chemistry.

These four disciplines have much in common - the scientists, the atoms and molecules and their reactions, the periodic table, the scientific literature, the institutions, educational and societal impact, industrial and commercial factors-but they differ greatly in culture, perspective, style, and language. This essay will focus on the following three questions:

- Are these disciplines isolated from each other?

- If so, what are the consequences of that isolation?

- How can the barriers between these disciplines be minimized in order to enhance the scholarship of each discipline, in particular, and the entire academy?

In 1978 historian Stephen Brush posed a question in the title of his essay Why Chemistry Needs History — and How It Can Get Some (Brush 1978). His first solution was

Chemistry teachers should use their influence in their own institutions to encourage the hiring of historians qualified to teach the history of science (Brush 1978).

Brush apparently was suggesting that chemists were unqualified to teach the history of their own science.

Chemist-historian-philosopher Steve Weininger wrote an essay in 2007 entitled "Letting the Scientists Back In" (Weininger 2007). Weininger borrowed that phrase from remarks made by British historian of science Martin J. S. Rudwick upon his retirement in 1998, when Rudwick said, as paraphrased by Weininger, that scientists

had been increasingly marginalized by historians of science over a period of several decades as the discipline [history of science] underwent professionalization. While scientists could hardly have been forbidden to write histories of science, their works were routinely dismissed... (Weininger 2007).

In 2015, Raf Vanderstraeten and Frederic Vandermoere (referred to as V\&V hereafter) published the paper Disciplined by the Discipline: A Social-Epistemic Fingerprint of the History of Science (Vanderstraeten and Vandermoere 2015) in the journal Science in Context, in which they concluded,

On the basis of an empirical analysis of Isis, we show how the process of disciplinebuilding in history of science has led its practitioners to be socialized and sensitized in relatively strong intra-disciplinary terms - with minimal interdisciplinary openness (Alder 2013; Nyhart 2013) ... In the 1950s and 1960s the history of science was a clear beneficiary of the university expansion (in the US especially). The ensuing disciplinary professionalization drove the amateurs out of the field (Vanderstraeten and Vandermoere 2015).

While "amateur historians of chemistry" were not driven completely out of the field in the 1950s and 1960s - note the many papers on the history of chemistry published by chemists in the Journal of Chemical Education in that time period-what did occur is that historians were able to isolate themselves from the scientists, a trend that continues today. V\&V cite recent papers by Ken Alder (Alder 2013) and Nyhart (2013) as having commented on the "minimal interdisciplinary openness" of historians of science, as judged by the publication history of Isis. In an email to this author, Alder wrote that $\mathrm{V} \& \mathrm{~V}$ had analyzed only the publication history of Isis, which 
certainly as the official society journal for HSS is 'exemplary.' But it is also perhaps the journal that is the most 'conservative' in the sense of being the most committed to creating a discipline out of this field of inquiry ... I do suppose that 'amateurs' such as, yes, scientists who study the history of their own disciplines - have been somewhat sidelined from the field in the past few decades, at least as compared to the field in the early 20th century and beforehand, when they were the principal practitioners. But such scientist-historians are still quite active, and I am personally all for multipronged approaches, and believe that many scientists have done tremendously important work (Alder 2017).

Now in its 64th volume, Ambix is the official journal of the Society for the History of Alchemy and Chemistry (SHAC). Alan Rocke, deputy editor of Ambix and a historian, recently said to me,

Please remember: Ambix is a history journal.

Indeed, an examination of the editorial boards of history of chemistry journals or of the names of the leaders of history of chemistry organizations reveal significant disciplinary segregation. Ambix and SHAC are populated mostly by historians, not chemists, as is the History of Science Society and the aforementioned history journals Isis and Osiris. The same has been and continues to be true for the Working Party on the History of Chemistry, a division of the European Association for Chemical and Molecular Sciences (EuCheMS) - the European equivalent of the American Chemical Society (ACS) (ironically and inconsistently, a chemical society, not a history society). To provide symmetry to this discussion, note that the editors of the ACS Division of History of Chemistry (HIST) journal, the Bulletin for the History of Chemistry, are all chemists, as have been almost all of HIST's leadership team for decades.

The opportunities and challenges of multidisciplinarity ${ }^{1}$ and interdisciplinarity ${ }^{1}$ have been discussed for years, and a journal Interdisciplinary Science Reviews is dedicated to the subject. Furthermore, recent studies focused on interdisciplinary research at the undergraduate (Gombrich 2016) and graduate level (Kaiser et al. 2014, 2016) have been analyzed in great detail and recommendations made. The focus on this paper is more organic: there is much evidence and discussion that entire new areas of science that require interdisciplinary collaborations are the next horizon in science (Whitesides 2015; Whitesides and Deutch 2011). How can such collaborations begin and flourish spontaneously, just as mono-disciplinary collaborative research programs begin? How do communication practices need to change so that meaningful interactions will happen organically? How can these lessons be extended to the history, philosophy and sociology of chemistry communities?

\section{Disciplinary isolation as a global phenomenon}

Disciplinary barriers, if not inhospitality, are by no means limited to chemistry and the history and philosophy of chemistry. This is likely a general phenomenon experienced across the academic universe. For example, in 2015 sociologists Marion Fourcade and colleagues published an article "The Superiority of Economists" (as compared to sociologists and political scientists) in the Journal of Economic Perspective (Fourcade et al. 2015). They concluded that economists, because of their reliance on mathematical analytical tools, claim superiority to explain economics over other professionals. Fourcade 
Table 1 Agreement or disagreement with the proposition: "In general, interdisciplinary knowledge is better than knowledge obtained by a single discipline." Source: Taken from Gross and Simmons's survey [Gross, N.: Why are professors liberal and why do conservatives care? Harvard University Press, Cambridge, MA (2013); Gross, N., Simmons, S.: The social and political views of American Professors. http:// citeseerx.ist.psu.edu/viewdoc/download?doi=10.1.1.147.6141\&rep=rep1\&type=pdf (2007). Accessed July 27, 2017]

\begin{tabular}{lllc}
\hline $\begin{array}{l}\text { American university } \\
\text { professors in }\end{array}$ & $\begin{array}{l}\text { \% Agree/strongly } \\
\text { agree }\end{array}$ & $\begin{array}{l}\text { \% Disagree/strongly } \\
\text { disagree }\end{array}$ & $\begin{array}{l}\text { \% No answer/don't } \\
\text { know }\end{array}$ \\
\hline Economics & 42.1 & 57.3 & 0.6 \\
Sociology & 72.9 & 25.3 & 1.8 \\
Political science & 59.8 & 28.0 & 12.2 \\
Psychology & 78.7 & 9.4 & 11.9 \\
Finance & 86.6 & 9.6 & 3.8 \\
History & 68.2 & 31.7 & 0.1 \\
\hline
\end{tabular}

et al. pointed out the insularity of economists, using a survey conducted in 2006 that showed that only $42 \%$ of economists agree with the proposition, "In general, interdisciplinary knowledge is better than knowledge obtained by a single discipline" (Fourcade et al. 2015). Of note, only $68 \%$ of the polled historians agreed that interdisciplinary knowledge is better. See Table 1.

While the goals of doing research are shared among the disciplines, their cultures, languages and methodologies differ significantly. Even the criteria for tenure at research institutions are quite different. For chemists, it is quality and number of journal publications and external funding. For historians, it is the quality and number of published books.

\section{McCarthyism in science history}

McCarthyism in academia (Rothman 1993) is making judgments about a publication or presentation or an individual's academic capabilities based on irrelevant factors such as gender, age, religion, place of birth or employment, rather than on performance criteria such as the quality of the person's publications and presentations. Exclusion of scholars from professional or academic circles solely because they do not hold advanced degrees in a particular field or hold an academic position in such a field is also McCarthyism. McCarthyism in any profession should be quarantined like a contagious disease.

McCarthyism in science history can cut both ways, especially in prejudice-producing situations like mono-disciplinary gatherings. For example, there is a kind of implicit condescension on the part of some scientists, who may be thinking, "You have to be a scientist to understand science and the way science is done. I had to be educated to do science, but I can do history (or sociology or philosophy) without any such education." Claims that chemistry, for example, has some kind of special epistemological status compared with history, or the converse, are discriminatory. Some historians also feel that they are under appreciated, if not overlooked. Historian of science Frank James recently revealed some degree of sensitivity if not competitive ownership, stating that 
In the media to this day there is a strong tendency to believe that only scientists (retired or otherwise) can comment publicly in non-specialist fora on the history of science or review books on the topic (James 2016).

\section{Authorship and readership strategies}

I now turn to another manifestation of disciplinary isolationism: the publication of articles that speak solely to members of one discipline. For several examples, I turn to this journal. According to its website,

Foundations of Chemistry is an international journal and an interdisciplinary forum in which chemists, biochemists, philosophers, historians, educators and sociologists discuss conceptual and fundamental issues which relate to the 'central science' of chemistry.

When I opened the table of contents of a recent issue of Foundations of Chemistry, I was immediately drawn to the article Isomerism and Decoherence by Fortin, Lombardi, and Martínez González (Fortin et al. 2016) due to my own interest in stereochemistry. I question how many readers of this journal understood the equations therein, to wit:

$$
\begin{gathered}
\hat{H}=\sum_{g}^{A} \frac{\hat{p}_{g}^{2}}{2 m_{g}}+e^{2} \sum_{g<h}^{A} \frac{Z_{g} Z_{h}}{2 m_{g}}+\sum_{i}^{N}\left(\frac{\hat{p}_{i}^{2}}{2 m_{e}}-e^{2} \sum_{g}^{A} \frac{Z_{g}}{r_{i g}}\right)+e^{2} \sum_{i<j}^{N} \frac{1}{r_{i j}} \\
P_{L \rightarrow R}=\left\langle R\left|e^{-i \frac{\hat{H}^{\hbar}}{\hbar} t}\right| L\right\rangle=\left|\sin \left(\frac{\omega_{1}-\omega_{0}}{2 \hbar} t\right)\right|^{2} \\
\hat{\rho}_{\text {measured }}=\frac{1}{2}|L\rangle\left\langle L\left|+\frac{1}{2}\right| R\right\rangle\langle R| \\
\left|\varphi_{S E}\right\rangle=\left|\omega_{0}\right\rangle \otimes\left|\varepsilon_{0}\right\rangle=\frac{1}{\sqrt{2}}|L\rangle \otimes\left|\varepsilon_{0}\right\rangle+\frac{1}{\sqrt{2}}|R\rangle \otimes\left|\varepsilon_{0}\right\rangle
\end{gathered}
$$

A reader of an early version of this essay questioned "the rhetorical effectiveness of basing your [Seeman's] point on one paper (Fortin et al.) and saying that you could have chosen other examples." That question initiated a several months-long experiment including numerous subsequent drafts in which I inserted concluding paragraphs from several articles from this journal. I pointed out that those concluding paragraphs were nearly incomprehensible to the average reader. I shared those drafts with the authors of those excerpts and with other colleagues. Following those discussions, I reversed course and deleted those excerpts. One author wrote,

It is not a good idea to quote from the concluding or last sentences in order to demonstrate your critique. Such sentences heavily rely upon the body of the text, in which the clarification and explication of the terms and abbreviations used in the last sentences have been or should be made. The last sentences may make not much sense without this context. So such uprooted examples can simply mislead.

But the dialogue with these authors proved illuminating. Several authors pointed out that they was not at all interested in crafting titles, abstracts and concluding sections that were easily understandable in the absence of reading the entire article. They felt that those 
who were truly intellectually captivated by the subject would read their papers regardless. One wrote,

I always read what interest me, even if the title and the abstract are not clear enough before reading the paper itself. Sometimes, a somewhat enigmatic title or abstract raises even more my desire to read the paper and to learn something entirely new. For me, intellectual interest is decisive, and if the paper is not easy to access, my interest outweighs this difficulty. I do not wish to make my life easier; I would like to make it more interesting. I believe that I share this wish with many intellectuals.

A philosopher of science wrote to me that abstracts

cannot be property done in philosophy, in which arguments, reasons, and clarifications are vital. The abstract is simply meant to evoke the curiosity of the potential readers and to make them read the paper carefully with critical eyes, attentive to details.

Apparently, many authors are intentionally writing primarily, if not solely, for their own (narrow) niche of specialists, not to readers who come from other disciplines. Such authors are consequently isolating themselves and their research achievements. Why would authors voluntarily limit the readership of their articles by not writing more clearly and more accessibly, by at least writing understandable titles, abstracts and conclusion sections? This isolationism is often assisted by our own professional societies and our journals' editors, reviewers, and even readers.

Readers can isolate themselves, too. Scientists have reported that they are so overcommitted, they cannot read all they papers they would like to read, and papers that are slightly outside their day-to-day research do not read, even a cursory scan (Collins 2014). If there is no immediate, direct and functional intellectual engagement, there is no time for the paper. But I claim that these decisions are not always black and white. There surely are papers which we see and wonder: Is this of interest or not? Readers, especially on-line readers, rely on titles and abstracts to make their reading decisions. Should authors not improve the readers' ability to make advantageous as well as practical choices?

\section{Dumbing down science}

A learned colleague who equally could not understand Forten et al. warned that

The article you rail against is indeed not comprehensible, but that's your and my weakness.

I fully accept and even anticipated that admonition. Below, I discuss the absolute need for unidisciplinary research, publications, lectures, etc. But as discussed throughout this essay, that justification cannot be an automatic rationalization but rather reserved, intentionally and consciously, for scientific necessities. There surely must be a penumbra, a meeting ground where communication is enhanced and broader interaction is encouraged and facilitated. 


\title{
Expanding the value of our research by expanding the readership of our papers
}

It is surely in the interest of the authors themselves, as well as the editors and the publishers of journals, to have as many as possible read, understand and value the papers published therein.

One might ask: What are the objectives of a scientific publication? I posit that, for a scientist, it is not enough for a paper to get published. Rather, that paper needs to be read, valued and used. That paper needs to make a difference.

(Yes, authors can reap tangible rewards from publication in peer-reviewed journals even if no one reads their papers. Authors enhance their curriculum vitae with collateral benefits.)

Authors should be more concerned than the editors and publishers about the readership of papers in journals. Will a journal suffer all that much if few, or any, scientists actually read a specific paper in this or that issue of a journal? Not really. Only if most papers are unintelligible to a wide slice of possible readers of the journal will the editors and the publishers take notice (or their journals eventually will fail). But for any one article and its authors, readership is critically important. If no one reads one's papers, authors might just as well have gone on an extended holiday and sat at the beach rather than having done the research and written the manuscripts.

How, then, do authors present complex results, often quite specialized, and communicate effectively and persuasively, to both the uninitiated and their own peer group, without diluting a publication's scholarship or devitalizing its spirit? Effective titles and abstracts are one way. The publishers of the journal Studies in History and Philosophy of Science have begun to address this challenge by including "Highlights"- three to five short bullet statements- that appear just below the article title, page range, and author in the journal's on-line Table of Contents. In some instances, the Highlights are more understandable than the article's abstract. Ultimately, it is up to the authors and journal editors and publishers to address these matters in their own idiosyncratic ways.

Much has been said about the difficulties of communicating science effectively to nonscientists (Shapin 2010). In the moment, I am talking about communicating science effectively to scientists who are educated and formally based in orthogonal disciplines.

\section{Other consequences of disciplinary isolationism}

\author{
Just recently Hasok Chang said that
}

From members of the public, from science educators, from practicing scientists, we professional historians of science often get very skeptical questions about the usefulness of our work (Chang 2017).

Today, history of science is under attack. Witness the merging of history of science departments within history departments and fewer academic slots for these disciplines. The isolationistic tendencies of the disciplines remind one of trade unions that exclude outsiders whatever their skills. Do not trade unions suffer in external support when their activities seem more self-serving and separate from the needs of the wider community? Thus, one consequence of disciplinary melding is building useful connections with others 
including those outside the sciences and history of science. Building bridges can only help the discipline of history of science.

\section{Examples of interdisciplinary activities}

The call for bridging the gap among the disciplines is not new. Indeed, formed in 1989, the International Society for History, Philosophy, and Social Studies of Biology (ISHPSSB) "brings together scholars from diverse disciplines, including the life sciences as well as history, philosophy, and social studies of science... fostering informal, co-operative exchanges and on-going collaborations." A past president of ISHPSSB, Lynn Nyhart, praised this as an organization

where the barriers to participation were deliberately low so that we could all learn from one another, including biologists seeking to dip their toes into history and philosophy of biology. It has been a great experiment. Its biennial meetings are a place where I know I'll meet philosophers willing to go beyond 'p-not-p' and biologists willing to talk about the meaning of their work, as well as other historians of biology. It used to be the case that all sessions had to be interdisciplinary, but that has been hard to maintain. It has been very interesting to participate in and watch the struggles to maintain parity across disciplines and hold open lines of communication. It is hard work (Nyhart 2017).

Perhaps the Chemical Heritage Foundation (CHF) can provide leadership toward interdisciplinary research in history, philosophy and sociology of chemistry and of other sciences. With its recent merging with the Life Sciences Foundation, CHF has an added incentive toward interdisciplinarity. I know full well that many individual CHF staff members are committed to interdisciplinarity and are making efforts toward that goal. For example, its President, Robert Anderson, has expressed a keen desire for better understanding by historians and chemists of disciplines other than their own. Anderson is planning an interdisciplinary meeting at CHF in late 2018 to address this topic.

CHF, HIST, SHAC, the Royal Society of Chemistry's History Group, the European Working Party on the History of Chemistry, and other organizations could make improved and sustained efforts to encourage interdisciplinarity among those interested in the story of chemistry, just as does ISHPSSB for the story of biology. One way to achieve that goal is to be as inclusive as possible, in terms of proactively seeking out disciplinary diversity in membership and leadership positions in these organizations. For a notable example, much to the credit of the Division of History of Chemistry of the ACS, Ronald Brashear, a historian and Director of the Othmer Library at CHF — and not a chemist-is currently HIST's Chair.

\section{The value of disciplinarity. An important caveat}

A reviewer of this paper wrote,

Many chemistry papers (as you point out) are incomprehensible to most people other than specialists and I personally don't see any problem with experts talking to other experts. So I am equally happy for historians and philosophers to use their own professional jargon which may not be accessible to others. 
The effort to broaden interest in a subject must not simultaneously work against the development and promulgation of that subject. I emphasize: My call for multiple disciplinarity is not always the best policy. There will be times when writing for a sharplydefined, single discipline is both optimal and necessary. But even in those instances, a callout containing a gray-boxed text entitled What This Paper Has Achieved could still serve the broader audiences.

The protection of disciplinarity, as important and valid as it can be, must not be blindly executed. Simultaneously, diversity of scholarship should not be discouraged solely on the basis of discipline-specific stylistic or cultural norms.

Surely, to write good history of science, one must do as historians do (and do increasingly), that is, draw on relevant techniques and literature from adjacent disciplines, which might be sociology, psychology, philosophy and of course, the science itself. Writing the history of science is difficult and may require specialized language, especially if one is at the leading edge of a subject. But there is a difference between the complexity of a subject and the comprehensibility of a manuscript.

\section{A novel call for action}

In his 2017 paper referenced above, historian Chang concluded that one of the complementary functions of the historians and philosophers of science

is to generate and improve scientific knowledge where science itself fails to do so... What better people to take up such neglected aspects of scientific knowledge, than historians and philosophers of science? (Chang 2017)

Chang then reported on simple electrochemical experiments that he personally performed to

exten[d] neglected knowledge that we [historians of science] recover from the past... At this point many historians will be questioning whether I am still doing history: are these investigations not just science, rather than history of science? That question does not trouble me greatly, as I see the boundary between science and the history of science as moveable and permeable... I hope that I have done enough to illustrate the possibility that the history of science may serve the internal function of improving scientific knowledge itself... (Chang 2017).

\section{An uphill and disruptive climb}

Chang's exhortation, even preaching for transdisciplinary migration was from one historian to his own peer group. It can also be a call for all members of the various disciplines related to chemistry and the history and philosophy of chemistry to recognize and act upon the "moveable and permeable boundaries" between the disciplines. But then, who will be the customers for the resultant publications? If the audience is a member of an aligned discipline, then the "outsider author" must do far more than use specialized jargon. To publish in journals outside one's own home discipline requires expressing oneself, and perhaps even thinking, in new, additional ways. And it requires editors to be open to 
intellectual contributions from authors outside their discipline and written in a somewhat foreign format. To take the easier route and publish solely in one's own discipline risks isolating one's research findings from the audiences that are most likely to benefit from those findings. And for the editors to reject submissions solely on the basis of style is shortsighted and a self-defeating posture.

According to Carin Berkowitz of the CHF,

True interdisciplinarity is hard, it is uncomfortable, it is transgressive, and it is risky. It is often a matter of forging temporary and explosive partnerships around particular kinds of questions. It is safer in spaces where less is at stake. It means not only borrowing tools or talking across audiences, or even being rigorously trained in two areas, but having questions, modes of work, and modes of communication that cross disciplines (Berkowitz 2017).

But Berkowitz then reflected on the challenges she has encountered publishing her book that

doesn't fit conventional boxes very well... Disciplines still hold sway, and publishers have already expressed concern that such a work doesn't clearly identify its audience... I hope from my position outside the academy, with less at stake in abiding by conventional rules, I can do the hard work that interdisciplinarity requires (Berkowitz 2017).

I would also counter that more is at stake, not less as Berkowitz suggests. The threat that ideas will be pigeonholed due to disciplinary protectionism is simply counterproductive to scholarship. Hard work and risk-taking must be shared by those publishers and editors of journals boasting their multiple disciplinary mission.

\section{A vision for the future}

It may well be that disciplinary formation (and enthusiastic pursuit and promotion) is necessary before one can engage in multiple disciplinarity. But as soon as possible, the doors for multiple disciplinarity should open and many should rush through. This is well exemplified by the discipline of chemistry. Because chemistry is sufficiently mature as a discipline today, many chemists participate in interdisciplinary research programs ranging from biomedical engineering to environmental science. In his recent article of the future of chemistry entitled "Reinventing Chemistry," George Whitesides proposed 24 "New Classes of Problems," all of which are interdisciplinary especially the 24th, which is "Combinations with adjacent fields" (Whitesides 2015). The ACS increasingly creates new, specialized yet multiple disciplinary journals and focuses on chemistry being a central science. Indeed, the title of a new ACS journal is ACS Central Science.

The opportunities are there for researchers, journals, and various history-oriented professional organizations to make more out of what we do and to fight McCarthyism in the history, philosophy and sociology of science. It is for all of us to open our eyes and our minds to the ideas and the words of those beyond our individual disciplines. These professions would be enhanced if all of the professional organizations whose mission includes "the history of chemistry" looked closely at their staff and those holding leadership positions and asked themselves, "Are we professionally diverse?" And then act on their answers. 
It is also time for all of us to write and to lecture in such a way that broader communities can understand, value, and benefit from the entire body of scholarship. As historian Robert Multauf wrote in 1986 on the occasion of his receiving the Dexter Award of the Division of History of Chemistry of the ACS,

What better could we do than write something that people would actually enjoy reading? There is plenty of evidence that there is an audience for that (Multhauf 1986).

There are myriad reasons for us to collaborate, to have joint symposia, to welcome a diverse leadership team in our history-oriented professional societies and journal editorial boards, and to enlarge the readership and readability of our own publications. I predict that the brightest and most imaginative of us, and the most visionary organizations and journals, will do so in the future.

Acknowledgements I thank Ken Alder, Robert Anderson, Carin Berkowitz, Leon Gortler, Roald Hoffmann, Frank James, Lynn Nyhart, Alan Rocke, Eric Scerri, Raf Vanderstraten, and Steve Weininger for valuable discussions and, along with several reviewers and other colleagues, for intense discussions and helpful suggestions.

\section{References}

Alder, K.: The history of science as oxymoron: from scientific exceptionalism to episcience. Isis 104, 88-101 (2013)

Alder, K.: email to Seeman, J.I., Evanston, IL, February 23, 2017

Berkowitz, C.: New illuminations: art-NATURE-History. In: Madison, W.I., Nyhart, L., (eds.) Paper Presented at the Burdock-Vary Symposium, University of Wisconsin, Conference Organizer, 3-4 March 2017

Brush, S.G.: Why chemistry needs history-and how it can get some. J. College Sci. Teach. 7(May), 288-291 (1978)

Chang, H.: 2015 Wilkins-Bernal-Medawar Lecture: who cares about the history of science? Notes Rec. 71, 91-107 (2017)

Choi, B.C., Pak, A.W.: Multidisciplinarity, interdisciplinarity And transdisciplinarity in health research, services, education and policy: 1. Definitions, objectives, and evidence of effectiveness. Clin. Invest. Med. 29, 351-364 (2006)

Collins, H.: Rejecting knowledge claims inside and outside science. Soc. Stud. Sci. 44, 722-735 (2014)

Fortin, S., Lombardi, O., González, J.C.M.: Isomerism and decoherence. Found. Chem. 18, 225-240 (2016)

Fourcade, M., Ollion, E., Algan, Y.: The superiority of economists. J. Econ. Perspect 29, 89-114 (2015)

Gombrich, C.: What sort of interdisciplinary research can undergraduates do? Interdisc. Sci. Rev. 41, 332-334 (2016). doi:10.1080/03080188.2016.1256590

James, F.A.J.L.: Introduction: some significances of the two cultures debate. Interdiscip. Sci. Rev. 47, 107-117 (2016)

Kaiser, M.I., Kronfeldner, M., Meunier, R.: Interdisciplinarity in philosophy of science. J. Gen. Philos. Sci. 45, 59-70 (2014)

Kaiser, M.I., Kronfeldner, M., Meunier, R.: Problems and prospects of interdisciplinarity: the case of philosophy of science. Interdisc. Sci. Rev. 41, 61-70 (2016). doi:10.1080/03080188.2016.1171583

Multhauf, R.P.: Dexter Award Address: Some Observations on the History of Chemistry, Newsletter of the Division of History of Chemistry of the American Chemical Society Number 16 (Spring), 4-6 (1986)

Nyhart, L.: email to Seeman, J.I., Madison, WI, March 8, 2017

Nyhart, L.K.: The shape of the history of science profession, 2038: a prospective retrospective. Isis 104, 131-139 (2013)

Rothman, K.J.: Conflict of interest. The new McCarthyism in science. J. Am. Med. Assoc. 269, 2782-2784 (1993)

Shapin, S.: Never Pure: Historical Studies of Science as if it Was Produced by People with Bodies, Situated in Time, Space, Culture, and Society, and Struggling for Credibility and Authority. Johns Hopkins University Press, Baltimore, MD (2010) 
Vanderstraeten, R., Vandermoere, F.: Disciplined by the discipline: a social-epistemic fingerprint of the history of science. Sci. Context 28, 195-214 (2015)

Weininger, S.J.: Letting the Scientists Back In. In: Gavroglu, K., Renn, J. (eds.) Positioning the History of Science, in Boston Studies in the Philosophy of Science, vol. 248, pp. 173-176. Springer, Dordrecht (2007)

Whitesides, G.M., Deutch, J.: Let's get practical. Nature 469, 21-22 (2011)

Whitesides, G.M.: Reinventing chemistry. Angew. Chem. Int. Ed. 54, 3196-3209 (2015) 